\title{
Active constituent of Polygala tenuifolia attenuates cognitive deficits by rescuing hippocampal neurogenesis in APP/PS1 transgenic mice
}

Xiao-feng Wang ${ }^{1 \dagger}$, Hong-he Xiao ${ }^{2 \dagger}$, Yu-tong Wu ${ }^{2}$, Liang Kong ${ }^{2}$, Ji-cong Chen², Jing-xian Yang ${ }^{2 *}$ and Xiao-le Hu ${ }^{1^{*}}$

\begin{abstract}
Background: Alzheimer's disease (AD) is the most common dementia worldwide, and there is still no satisfactory drug or therapeutic strategy. Polygala tenuifolia is a traditional Chinese medicine with multiple neuroprotective effects. In present study, we investigated the effects of three active constituents [3,6'-disinapoyl sucrose (DISS), onjisaponin B (OB) and tenuifolin (TEN)] of Polygala tenuifolia (PT) on the proliferation and differentiation of neural stem cells (NSCS) to identify the potential active constituent of PT promoting hippocampal neurogenesis.

Methods: NSCs were isolated from hippocampi of newborn C57BL/6 mice, and transfected with mutant amyloid precursor protein (APP) gene to establish an AD cell model (APP-NSCs). 3-(4,5- Dimethylthiazol-2-yl)-2,5-diphenyltetrazolium bromide (MTT) and lactate dehydrogenase (LDH) assays were performed, and the proliferation and differentiation of NSCs were assessed by neurosphere formation assay, 5-bromo-2'-deoxyuridine (BrdU) incorporation assay and immunofluorescence (IF) staining analysis. APP/PS1 transgenic mice were administrated with the potential active constituent DISS for 4 weeks. Morris water maze (MWM), Nissl staining assay and IF staining assays were carried out to evaluate the cognitive function, neural damages and hippocampal neurogenesis, respectively.
\end{abstract}

Results: DISS exerted the optimal ability to strengthen APP-NSCs proliferation and neuronal differentiation, followed by OB and TEN. Furthermore, DISS treatment for 4 weeks strikingly rescued the cognitive deficits, neuronal injures, and neurogenesis disorder in adult APP/PS1 transgenic mice.

Conclusions: Our findings demonstrated that DISS is the constituent of PT that triggers the most potent increase of hippocampal neurogenesis in our mouse model of AD.

Keywords: Alzheimer disease, Neurogenesis, Neural stem cells, Polygala tenuifolia, 3,6'-disinapoyl sucrose

*Correspondence: jingxianyang63@126.com; 280617642@qq.com †Xiao-feng Wang and Hong-he Xiao contributed equally to this work. ${ }^{1}$ Center for Neuromedicine of Dalian Municipal Central Hospital, 42 Xuegong Street, Shahekou District, Dalian, Liaoning Province 116033, People's Republic of China

${ }^{2}$ School of Pharmacy, Liaoning University of Traditional Chinese Medicine, 77 Life One Road, DD Port, Dalian, Liaoning Province 116600 People's Republic of China

\section{Background}

Alzheimer's disease (AD) is a neurodegenerative disorder associated with extensive symptoms, including progressively declines in language, cognitive and orientation functions, which result in dysfunction in personality and behavior [1]. Currently, AD is insulting more than 50 million individuals worldwide. Moreover, along with the aggravated aging of world's population, the risk of developing $\mathrm{AD}$ increases, which will lead to a tremendous 
socio-economic challenge. Unfortunately, no drugs or agents are available to treat or to prevent the disease right now [2]. AD is characterized by neuropathological hallmarks, including neurofibrillary tangles (NFTs), senile plaques (SPs) formed by amyloid beta (A $\beta$ ) accumulation, chronic neuroinflammation, synapse loss and neuronal death $[1,3,4]$. In addition, dysfunction of hippocampal neurogenesis has been identified in both $\mathrm{AD}$ patients and AD rodent models [5-7].

Adult hippocampal neurogenesis is the process that continually generates new neurons from neural stem cells (NSCs) in the hippocampus, and plays is a vital role in hippocampal plasticity and cognitive function [8]. It has been well demonstrated that adult hippocampal neurogenesis persists throughout the lifetime in mammals and human beings [9]. However, this process decreases with aging and neurodegenerative diseases including AD. New born neurons are still detectable in AD patients, the amount is severely lower than that in age-matched healthy controls [10-12]. A growing body of literature indicates that deficits of hippocampal neurogenesis are already observed at a pre-symptomatic stage of $\mathrm{AD}$, which further aggravate the cognitive disorder of this disease [5-7]. Thus, extensive efforts are underway to exploit feasible approach to stimulate endogenous neurogenesis in the hippocampus of AD brains. Fortunately, compounds such as metformin and $\beta$-asarone which can modulate stages involving proliferation, migration, and differentiation of NSCs development would promote hippocampal neurogenesis to ameliorate cognitive function in adult rodents [13, 14].

Polygala Tenuifolia (PT), also known as Yuan Zhi in Chinese, is a famous traditional Chinese medicine which has been widely applied to treat central nervous system diseases including dementia and neurasthenia [15]. Numerous pharmacological studies have demonstrated that PT possessed multiple neuroprotective effects associated with AD, such as anti-apoptosis [16], anti-neuroinflammation [17], enhancing neurotrophy $[18]$ and anti-neurotoxicity induced by $\beta$-amyloid $(A \beta)$ [19]. Moreover, it has been reported that PT extract promoted NSCs proliferation in vitro and enlarged the amount of NSCs in hippocampal CA1 regions in adult rats [20]. Phytochemical studies have revealed that there are more than 100 compounds including saponins, xanthones, and oligosaccharide esters in PT [21]. Onjisaponin B (OB), 3,6'-disinapoyl sucrose (DISS) and Tenuifolin (TEN) are the major active constitutes of PT. Previous studies have revealed that OB could mitigate the cognitive impairments by elimination of neuroinflammation, oxidative stress and $A \beta$ pathology in AD animals [22, 23]. DISS could protect SH-SY5Y cells from apoptosis induced by glutamate [24, 25]. TEN is a metabolite of OB [26], and it has been demonstrated that oral administration of TEN markedly improved the cognitive function of $\mathrm{AD}$ animals [27, 28]. However, the potential active constituent of PT to promote the proliferation of NSCs and whether it could promote hippocampal neurogenesis in APP/PS1 mice are still relatively unexplored.

In present study, using the NSCs overexpressed amyloid precursor protein (APP-NSCs) as the AD cell model $[29,30]$, we sought to investigate the potential beneficial effects of the three active constituents of PT mentioned above on the survival, proliferation and differentiation of APP-NSCs in vitro, and further evaluate the effects of the potential active constituent DISS on the hippocampal neurogenesis in adult APP/PS1 transgenic mice.

\section{Materials and methods Chemicals and reagents}

The 3,6'-disinapoyl sucrose (DISS, Lot: JOT10848, purity $>98 \%$ ), Onjisaponin B (OB, Lot: JOT10575, purity $>98 \%$ ) and Tenuifolin (TEN, Lot: JOT10162, purity $>98 \%$ ) were purchased from the Chengdu Pufei De Biotech Co., Ltd. (Chengdu, China). The 5-bromo2'-deoxyuridine (BrdU, Lot: MB3126-2) was purchased from Dalian Meilun Biotechnology Co., Ltd. (Dalian, China). Dulbecco's modified Eagle's medium (DMEM)/ F12 medium, B27 supplement (Lot: 17054-044), nonessential amino acid (NEAA, Lot: 11140050), and GlutaMAX supplement (Lot: 35050061) were obtained from Gibco. Fetal bovine serum (FBS) was obtained from Invitrogen (Carlsbad, CA, USA). Basic fibroblast growth factor (bFGF, Lot: 100-18C) and epidermal growth factor (EGF, Lot: 315-09) were purchased from PeproTech company (Suzhou, China). The lactate dehydrogenase (LDH) kit was purchased from Nanjing Jiancheng Biotechnology, Co. (Nanjing, China). The primary antibodies including Rabbit anti Nestin (Lot: bs-20607R), Rabbit anti glial fibrillary acidic protein (GFAP, Lot: bs-0199R), Rabbit anti intermediate neurofilament (NF-M, Lot: bs-0710R), and Mouse anti BrdU (Lot: bs-0917R) were purchased from Beijing Bioss Biotechnology Co., Ltd. (Beijing, China). Mouse anti sex-determining region Y-box 2 (Sox-2, Lot: GT1876), Rabbit anti neural/glial antigen-2 (NG-2, Lot: PA5-27452), and Mouse anti neuron-specific nuclear protein (NeuN, Lot: MA5-33103) were purchased from Invitrogen (Carlsbad, CA, USA). The secondary antibodies labeled $\mathrm{Cy} 3$ or fluorescein isothiocyanate (FITC) were purchased from Jackson ImmunoResearch Inc. (West Grove, PA, USA). The chemical constructions of the three compounds were as shown in Fig. 1 A-C. 


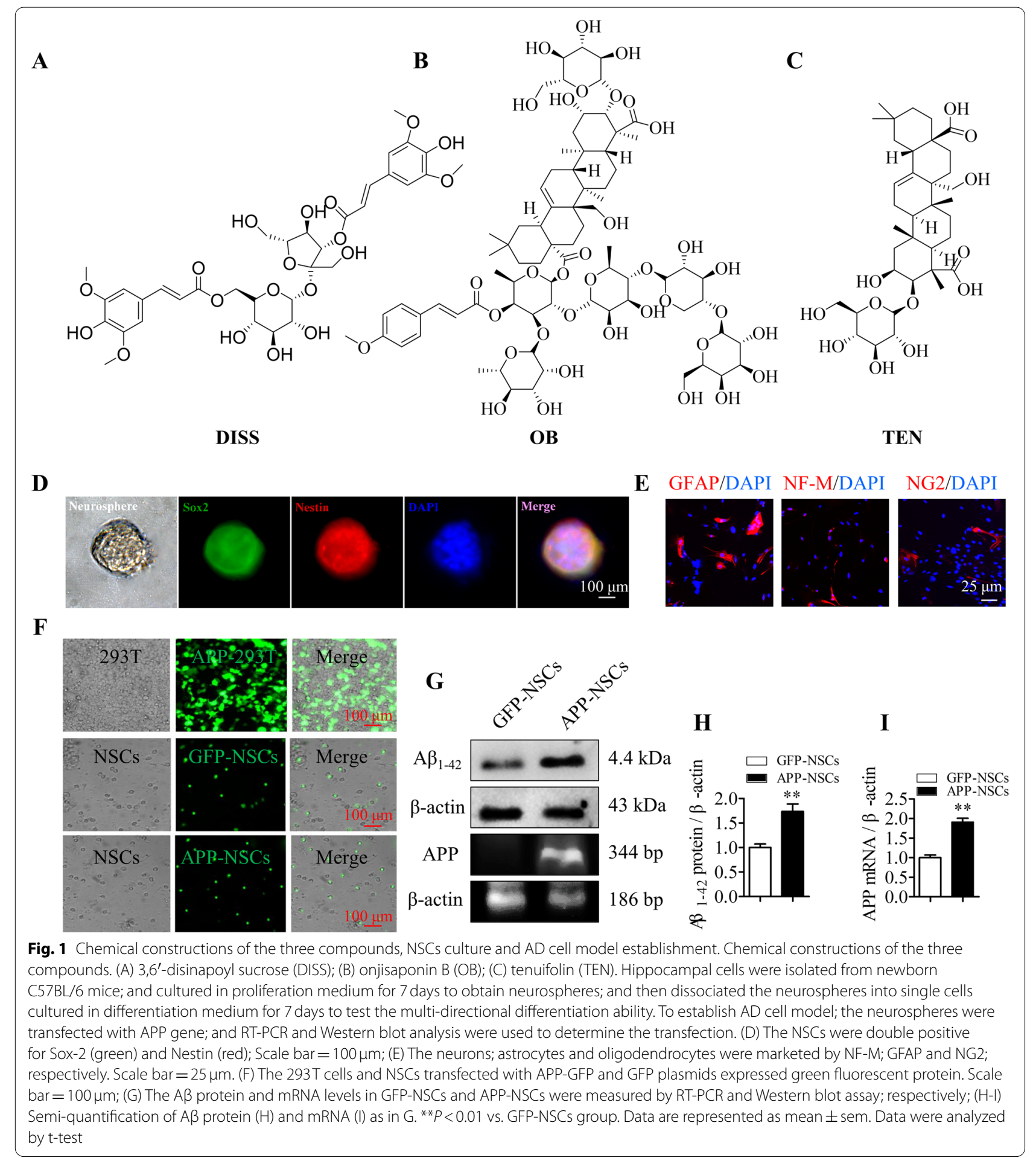

\section{Animals}

APP/PS1 mice were purchased from the Model Animal Resource Information Platform (Nanjing, China). The littermate wild-type (WT) male C57BL/6 mice were used as normal control. Mice were aged about 9-month-old at the time of experiments ( $n=10$ in each group). All the mice were acclimated on a condition with access to mouse chow and water for 7 days before experiments. The temperature was $23 \pm 2{ }^{\circ} \mathrm{C}$, the humidity was $65 \pm 5 \%$, and the illumination was $12 \mathrm{~h}$ light $/ 12 \mathrm{~h}$ dark cycle. 
New-born C57BL/6 mice were used for isolation and culture of NSCs in vitro. All experiments were approved by the Animal Core and Welfare Committee of Liaoning University of Traditional Chinese Medicine (use license number: SYXK (Liao) 2019-0004). All animal experiments complied with the ARRIVE guidelines and were carried out in accordance with Guide for the Care and Use of Laboratory Animals published by the US National Institutes of Health (NIH Publication No. 85-23, revised 1996).

\section{NSCs culture and AD cell model establishment}

The NSCs culture and APP genes transduction were carried out as described in our previous studies [30, 31]. Briefly, the hippocampal cells isolated from new-born C57BL/6 mice were cultured in proliferation medium for 7-10days. The proliferation medium consists of DMEM/F 12 medium supplemented with $1 \%$ non-essential amino acid (NEAA), 2\% B 27, 1\% GlutaMAX, $20 \mathrm{ng} /$ $\mathrm{ml} \mathrm{EGF,} 20 \mathrm{ng} / \mathrm{ml} \mathrm{bFGF}$ and $0.5 \%$ penicillin/streptomycin. To identify the cultured NSCs, the neurospheres were underwent immunofluorescence staining (IF) against Nestin and Sox-2, respectively. To assess the multipotential differentiation, the cultured NSC suspensions were cultured in differentiation medium for 7 days, followed by IF staining against GFAP, NF-M and NG2, respectively. The differentiation medium consists of DMEM/F12 medium supplemented with $1 \%$ NEAA, $2 \%$ B27, $1 \%$ GlutaMAX, $1 \%$ fetal bovine serum (FBS) and $0.5 \%$ penicillin/ streptomycin.

The green fluorescent protein (GFP) and APP-GFP plasmids were obtained from Professor Ya-Ping Yan in Shaanxi Medical University. To achieve AD cell model, NSCs were transfected with APP-GFP lentiviral vector and GFP lentiviral vector, respectively, as described in our previous studies [30]. Three days later, the transfection efficiency was evaluated using by RT-PCR and Western blot analysis.

\section{Cell viability}

The cell viability was detected using by MTT assay. Briefly, single NSC suspension was seeded into 96-well plates at a density of approximately $1 \times 10^{6} \mathrm{cells} / \mathrm{ml}$, cultured in proliferation medium for $24 \mathrm{~h}$. Then, cells were exposed to DISS (20, 40 and $60 \mu \mathrm{M}), \mathrm{OB}(2.5,5$ and $10 \mu \mathrm{M})$ and TEN (20, 40 and $60 \mu \mathrm{M})$, respectively, for another $24 \mathrm{~h}$. After that, $10 \mu \mathrm{L}$ MTT $(5 \mathrm{mg} / \mathrm{mL})$ solution was added into each well, and incubated for $4 \mathrm{~h}$ in the $\mathrm{CO}_{2}$ incubator. Replace the culture medium with $100 \mu \mathrm{L}$ dimethyl sulfoxide to dissolve the formazan. The absorbance was measured at $532 \mathrm{~nm}$ using a microplate reader, and the cell viability of control group was normalized as $100 \%$.

\section{LDH assay}

Single NSC suspension was seeded into 96-well plates at a density of approximately $1 \times 10^{6}$ cells $/ \mathrm{ml}$, cultured in proliferation medium for $24 \mathrm{~h}$. Then, cells were exposed to DISS (20, 40 and $60 \mu \mathrm{M}), \mathrm{OB}(2.5,5$ and $10 \mu \mathrm{M})$ and TEN (20, 40 and $60 \mu \mathrm{M})$, respectively, for another $24 \mathrm{~h}$. After that, the culture medium was harvested for the detection of LDH using a LDH kit according to the manufacturer's instruction.

\section{Neurosphere culture}

As described previously [32], the GFP-NSCs and APPNSCs suspensions were seeded into 24-well plates at a density approximately of $1 \times 10^{5}$ cells $/ \mathrm{ml}$, and cultured in proliferation medium in the presence or absence of DISS $(60 \mu \mathrm{M}), \mathrm{OB}(10 \mu \mathrm{M})$ and TEN $(60 \mu \mathrm{M})$ for 7 days, respectively. The diameters of resulting neurospheres in different groups were measured using Image J software.

\section{BrdU labeling}

The GFP-NSCs and APP-NSCs suspensions were seeded into a 96-well plate coated with poly-D-lysine at a density approximately of $1 \times 10^{6} \mathrm{cells} / \mathrm{ml}$, cultured in proliferation medium in the presence or absence of DISS $(60 \mu \mathrm{M}), \mathrm{OB}(10 \mu \mathrm{M})$ and TEN $(60 \mu \mathrm{M})$ for $24 \mathrm{~h}$, respectively. Cells were incubated within $20 \mu \mathrm{M}$ of BrdU for $12 \mathrm{~h}$ to label proliferating cells, followed by IF analysis [32].

\section{NSCs migration assay}

Neurospheres about $200 \mu \mathrm{m}$ in diameter were plated into 24-well plates coated with poly-D-lysine, and cultured in differentiation medium. The neurospheres were exposed to $60 \mu \mathrm{M}$ of DISS, $10 \mu \mathrm{M}$ of OB and $60 \mu \mathrm{M}$ of TEN, respectively. After 3 days' exposure, pictures of the neurospheres were captured under an inverted microscope. Image-J software was applied to measure the migration distance of neural cells from the edge of the neurospheres [33].

\section{NSCs differentiation assay}

The GFP-NSCs and APP-NSCs suspension were plated into 96-well plates in proliferation medium overnight. Replaced the proliferation medium with the differentiation medium supplemented with or without DISS $(60 \mu \mathrm{M}), \mathrm{OB}(10 \mu \mathrm{M})$ and TEN $(60 \mu \mathrm{M})$, cultured in the incubator for 7 days, followed by IF analysis against GFAP (glial fibrillary acidic protein, astrocyte marker), NF-M (intermediate neurofilament, neuron marker), and NG2 (neural/glial antigen 2, oligodendrocyte marker) to 
investigate the effects of the three compounds on the differentiation of NSCs.

\section{IF staining assay for culture cells}

IF staining analysis was performed as described previously [14]. In short, cells were fixed with $4 \%$ paraformaldehyde (PFA) at $4{ }^{\circ} \mathrm{C}$ for $20 \mathrm{~min}$, permeabilized with $0.5 \%$ Triton X-100 at room temperature (RT) for $20 \mathrm{~min}$, blocked with $5 \%$ bovine serum albumin (BSA) for at RT for $60 \mathrm{~min}$, incubated with primary antibodies against GFAP (1:150), NF-M (1:200), NG2 (1:200) and BrdU $(1: 150)$ at $4{ }^{\circ} \mathrm{C}$ overnight, respectively. Cells were rinsed with PBS for 3 times, incubated with Cy3 or FITC-conjugated secondary antibodies at RT for $60 \mathrm{~min}$, counterstained with DAPI for 10-15 min to label the nuclei.

As to double-staining against Sox-2 and Nestin, cells were incubated within primary antibody mixture composed by mouse anti-Sox-2 (1:150) and rabbit anti-Nestin (1:150) for 18-24h, rinsed with PBS for 3 times, followed by incubation with secondary antibody mixture composed by Cy3-conjugated goat anti-rabbit and FITC-conjugated donkey anti-mouse secondary antibodies at RT for $60 \mathrm{~min}$.

As to BrdU staining, before blocking with 5\% BSA, cells were exposed to $2 \mathrm{M}$ of $\mathrm{HCl}$ at $37^{\circ} \mathrm{C}$ for $30-40 \mathrm{~min}$, rinsed with borate buffer $(\mathrm{pH}=8.5)$ for 3 times to neutralize the $\mathrm{HCl}$. The images were captured under random visual fields using an inverted fluorescence microscope (Nikon Eclipse E 800, Tokyo, Japan).

\section{Animals and drug administration}

DISS was prepared with $0.3 \%$ sodium carboxymethyl cellulose $(\mathrm{CMC}-\mathrm{Na})$ into solutions with concentrations of 0.5, 1 and $2 \mathrm{mg} / \mathrm{mL}$. Male APP/PS1 mice aged 9-monthold were randomly divided into the following 4 groups ( $n=10$ per group): model control group (APP/PS1), DISS-Low group $(5 \mathrm{mg} / \mathrm{kg})$, DISS-Middle group (10 $\mathrm{mg} /$ $\mathrm{kg})$ and DISS-High group $(20 \mathrm{mg} / \mathrm{kg})$. The dose of DISS was determined according to the preliminary screen and previous study [34]. Another 10 littermates of wild-type male C57BL/6 mice were taken as normal control (WT). Mice in DISS treatment groups were orally administrated with different doses of DISS mentioned above once a day for 28 days. Mice in APP/PS1 group and WT group were orally given $0.3 \% \mathrm{CMC}-\mathrm{Na}$ as vehicle.

\section{Morris water maze (MWM) test}

The MWM experiments were performed as described previously $[35,36]$. In short, a circular tank filled with $40 \mathrm{~cm}$ depth of water $\left(21 \pm 1^{\circ} \mathrm{C}\right)$ containing non-toxic white paint was used to perform the MWM experiments. In the training trials, individual mouse received two trainings per day for 5 consecutive days, and the escape latency was measured to evaluate the spatial acquisition capacity. After the last training trial, the probe test was performed. The mouse swam in the tank without escape platform for $120 \mathrm{~s}$, the platform crossing numbers and the time spent in the target quadrant were recorded to evaluate the memory ability.

\section{Tissue preparation}

After the MWM test, mice were sacrificed, perfused with cold saline to rinse the blood, followed by $4 \%$ PFA to fix the tissues. The brain tissues were dehydrated within $30 \%$ sucrose at $4{ }^{\circ} \mathrm{C}$ for $18-24 \mathrm{~h}$, embedded within optimal cutting temperature embedding medium, coronally sectioned into $10 \mu \mathrm{m}$ sections, stored at $-80^{\circ} \mathrm{C}$ until usage [37]. The hippocampal areas were checked in the Nissl staining assay and IF staining assays.

\section{Nissl staining assay}

Nissl staining assay was carried out to investigate the morphological impairments of neurons in the hippocampal regions according to the specification. In short, brain sections were fixed with $4 \%$ PFA at $4{ }^{\circ} \mathrm{C}$ for $20 \mathrm{~min}$, washed with cold PBS for 3 times, stained with Nissl staining solution (C0117; Beyotime Biotechnology) for $5 \mathrm{~min}$, rinsed with $95 \%$ ethanol for $5 \mathrm{~min}$, transparentized within dimethylbenzene, sealed with neutral gum. Microscopic images were captured using the Nikon Eclipse E 800 microscope (Nikon, Tokyo, Japan). Image J software was applied to count the number of Nissl bodies.

\section{IF staining assay for brain tissues}

Brain sections were fixed with cold PFA for $30-40 \mathrm{~min}$, permeabilizated with $1 \%$ Triton X-100 at RT for $30 \mathrm{~min}$, followed by blocking with 5\% BSA at RT for $60 \mathrm{~min}$. Sections were subsequently incubated with primary antibodies including mouse anti-Sox-2 (1:150), rabbit anti-Nestin (1:200), and mouse anti-NeuN (1:200), respectively, at $4{ }^{\circ} \mathrm{C}$ for $18 \mathrm{~h}$. Then, sections were rinsed with PBS for 3 times, incubated with $\mathrm{Cy} 3$ or FITC-conjugated secondary antibodies at RT for $1.5 \mathrm{~h}$, incubated with DAPI for $10 \mathrm{~min}$ to counterstain nuclei. The entire hippocampal regions including CA1, CA3 and dentate gyri (DG) regions were scanned.

\section{Statistical analysis}

Data were presented as the mean \pm sem. One-way ANOVA with Tukey post tests was applied to evaluate differences among multiple groups. Unpaired Student's $t$ test was applied to examine differences between two groups. Repeated-measures two-way ANOVA was used in the escape latency data in the MWM test. $P$-value less than $0.05(P<0.05)$ was considered statistically significant [38]. 


\section{Results}

\section{NSCs culture and AD cell model establishment}

After being cultured in proliferation medium for 7-10 days, the neural cells isolated from hippocampi of newborn C57BL/6 mice grew into neurospheres. The immunostaining results showed that these neurospheres were double-positive for Sox-2 and Nestin (Fig. 1 D). Cultured in differentiation medium for 7 days, the monolayer NSCs differentiated into astrocytes (GFAP $\left.{ }^{+} / \mathrm{DAPI}\right)$, neurons (NF-M $\left.{ }^{+} / \mathrm{DAPI}\right)$ and oligodendrocytes $\left(\mathrm{NG}^{+} / \mathrm{DAPI}\right)$ (Fig. $1 \mathrm{E}$ ), indicating the multipotent differentiation of the cultured NSCs.

To achieve AD cell model, the cultured NSCs were transfected with GFP and APP-GFP lentiviral vectors, respectively. As shown in Fig. $1 \mathrm{~F}$, green fluorescence was observed both in GFP-NSCs and APP-NSCs under a fluorescence microscope. The RT-PCR and Western blot results indicated that both mRNA and protein of APP and $A \beta_{42}$ were over-expressed in APP-NSCs compared with that in GFP-NSCs (Fig. 1 G-I). These results indicated that an AD cell model (APP-NSCs) overexpressing $A \beta_{42}$ proteins was established successfully.

\section{The effects of the three active ingredients on cell viability and damages of APP-NSCs}

The MTT results showed that the cell viability in APPNSCs was remarkably lower than that in GFP-NSCs (Fig. 2 A-C, \#\#P<0.01 vs. GFP-NSCs). After exposure to different compounds, the cell viability was does-dependently increased (Fig. $2 \mathrm{~A}-\mathrm{C}, * P<0.01$ in 40 and $60 \mu \mathrm{M}$ of DISS; ${ }^{* * P}<0.01$ in $10 \mu \mathrm{M}$ of $\mathrm{OB} ; * P<0.05$ in $60 \mu \mathrm{M}$ of TEN). Similarly, the three active compounds could all recused the excessive leakage of LDH in APP-NSCs

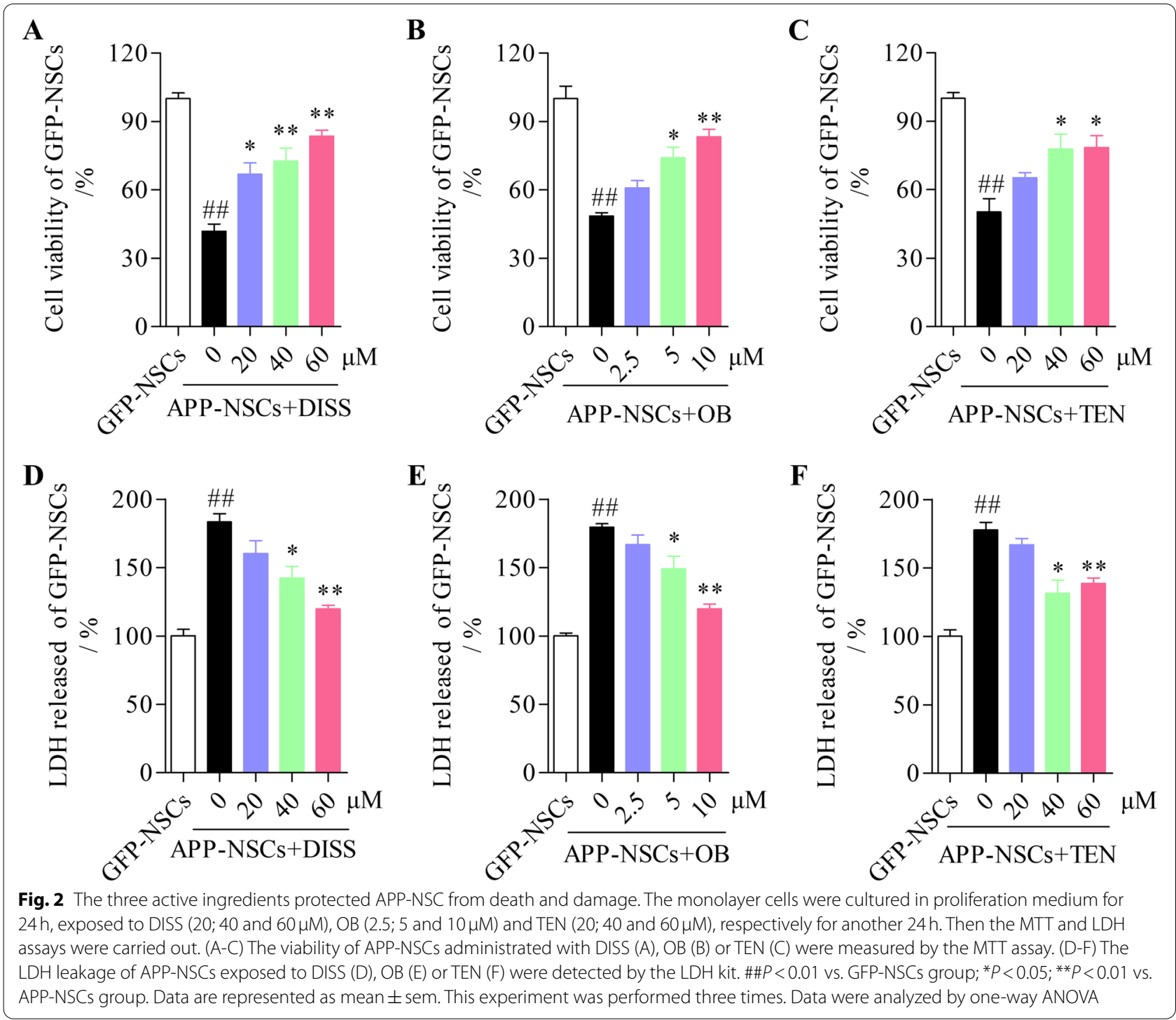




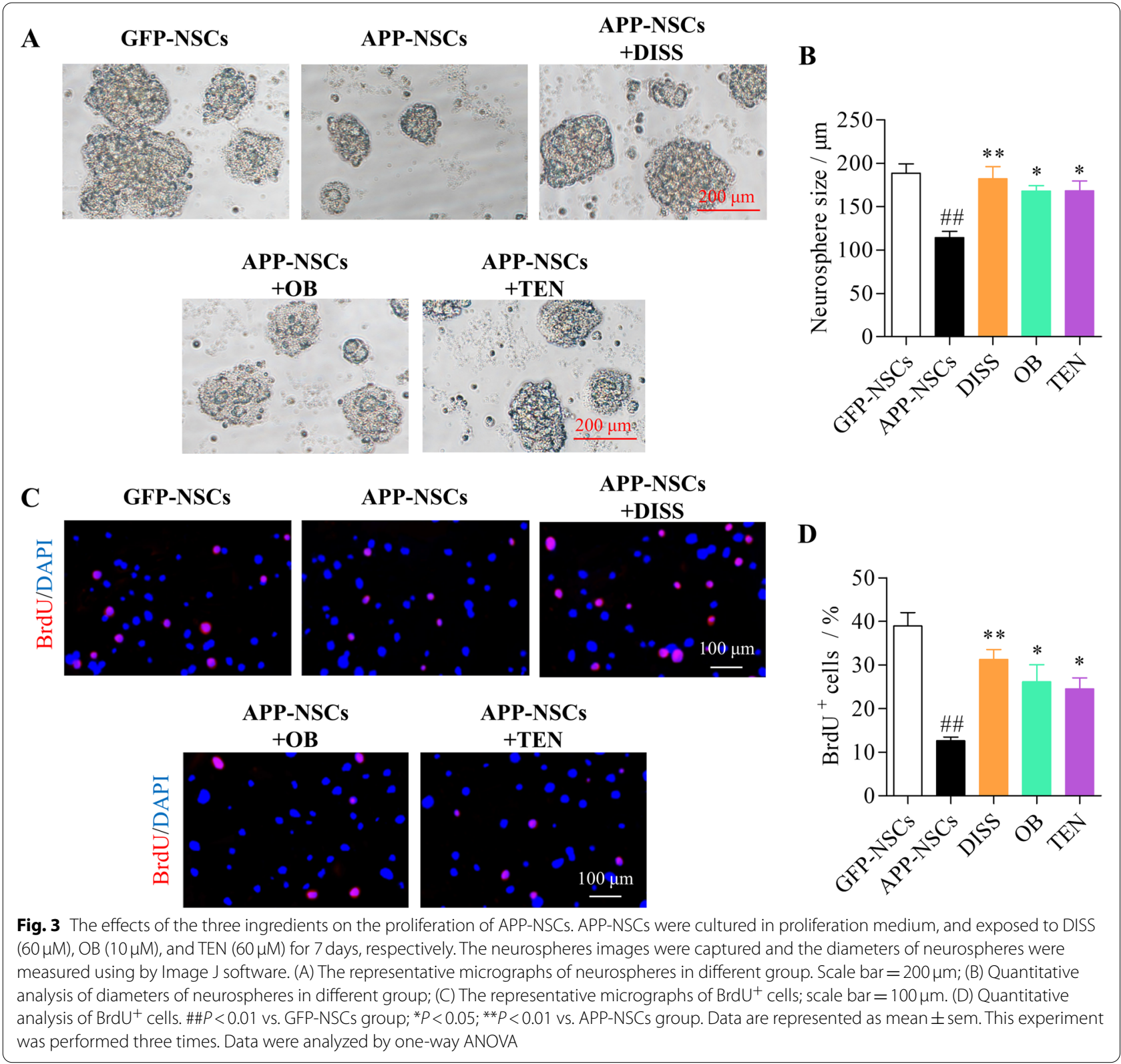

(Fig. $2 \mathrm{D}-\mathrm{F}, * * P<0.01$ in $60 \mu \mathrm{M}$ of DISS; $* P<0.01$ in $10 \mu \mathrm{M}$ of $\mathrm{OB} ;{ }^{* *} P<0.01$ in $60 \mu \mathrm{M}$ of TEN). These findings indicated that the three active compounds could protect APP-NSCs from death and damages. The optimal concentrations including $60 \mu \mathrm{M}$ of DISS, $10 \mu \mathrm{M}$ of OB and $60 \mu \mathrm{M}$ of TEN were used in the following experiments in vitro.

\section{The effects of the three active ingredients on proliferation of APP-NSCs}

As shown in Fig. 3, the size of neurospheres in APPNSCs group were remarkably decreased compared with that in GFP-NSCs group (Fig. $3 \mathrm{~A}-\mathrm{B}, \# \# P<0.01$ vs. GFPNSCs group). Whereas, APP-NSCs treated with $60 \mu \mathrm{M}$ of DISS, $10 \mu \mathrm{M}$ of $\mathrm{OB}$ or $60 \mu \mathrm{M}$ of TEN displayed enlarged diameters compared with that in APP-NSCs group (Fig. 3 A-B, DISS: ${ }^{* *} P<0.01$; OB: ${ }^{*} P<0.05$; TEN: ${ }^{*} P<0.05$ vs. APP-NSCs). Similarly, there were less BrdU-positive cells in APP-NSCs group (Fig. $3 \mathrm{C}-\mathrm{D}, \# \# P<0.01$ vs. GFP-NSCs group), but more BrdU ${ }^{+}$cells were observed in the three active ingredients treatment groups (Fig. 3 C-D, DISS: ${ }^{* *} P<0.01$; OB: $* P<0.05$; TEN: $* P<0.05$ vs. APP-NSCs). These results demonstrated that DISS, OB and TEN could partially rescued proliferation deficits of 
APP-NSCs. DISS possessed the optimal effect among the three compounds of PT.

\section{The effects of the three active ingredients on migration of APP-NSCs}

NSCs about $200 \mu \mathrm{m}$ in diameter were exposed to $60 \mu \mathrm{M}$ of DISS, $10 \mu \mathrm{M}$ of $\mathrm{OB}$ and $60 \mu \mathrm{M}$ of TEN for 3 days, respectively, followed by migration assays. The neural cells were observed to migrate radially outward from the emerge of the neurospheres (Fig. $4 \mathrm{~A}$ ). The migration distances of APP-NSCs were strikingly shorter as compared with that in GFP-NSCs (Fig. 4 A-B, \#\#P<0.01). DISS $(60 \mu \mathrm{M})$ and $\mathrm{OB}(10 \mu \mathrm{M})$ treatment prominently extended the migration distances (Fig. 4 A-B, ${ }^{* *} P<0.01$ in DISS; ${ }^{*} P<0.01$ in OB vs. APP-NSCs group). However, TEN could not increase the migration distances of APP-NSCs ("P>0.05 vs. APP-NSCs group). These results indicated that DISS $(60 \mu \mathrm{M})$ or OB $(10 \mu \mathrm{M})$ treatments partially recovered migration of APP-NSCs.

\section{The effects of the three active ingredients} on differentiation of APP-NSCs

As shown in Fig. 5 A-B, the percentage of astrocytes $\left(\mathrm{GFAP}^{+} / \mathrm{DAPI}\right)$ in APP-NSCs group increased (Fig. 5 $\mathrm{A}-\mathrm{B}, \# P<0.05$ vs. GFP-NSCs), the proportion of neurons
(NF-M ${ }^{+} / \mathrm{DAPI}$ ) decreased (Fig. 5 A-B, \#\#P<0.01 vs. GFP-NSCs), and the oligodendrocyte (NG2 $\left.{ }^{+} / \mathrm{DAPI}\right)$ percentage was not markedly altered (Fig. $5 \mathrm{~A}-\mathrm{B}, P>0.05$ vs. GFP-NSCs), indicating differentiation defects of APPNSCs. The astrocyte percentage in DISS $(60 \mu \mathrm{M}), \mathrm{OB}$ $(10 \mu \mathrm{M})$ and TEN $(60 \mu \mathrm{M})$ treatment groups were significantly decreased (Fig. 5 A-B, ${ }^{* *} P<0.01$ in DISS; ${ }^{*} P<0.05$ in $\mathrm{OB}$; ${ }^{*} P<0.05$ in TEN vs. APP-NSCs), and the neuron percentage in DISS $(60 \mu \mathrm{M})$ and OB $(10 \mu \mathrm{M})$ treatment groups were notably increased (Fig. $5 \mathrm{~A}-\mathrm{B},{ }^{* *} P<0.01$ in DISS; ${ }^{*} P<0.05$ in OB vs. APP-NSCs). However, TEN $(60 \mu \mathrm{M})$ has no significant effects on the differentiation of APP-NSCs (Fig. 5 A-B, P>0.05 vs. APP-NSCs). These results demonstrated that DISS $(60 \mu \mathrm{M})$ and $\mathrm{OB}$ $(10 \mu \mathrm{M})$ treatment could effectively rescue the differentiation defects of APP-NSCs. Moreover, DISS exerted optimal effect to promoting neuronal differentiation of APP-NSCs, thus DISS was used in the following in vivo experiments.

\section{DISS rescued cognitive deficits in adult APP/PS1 mice}

MWM test was carried out to assess the learning and memory ability of mice in different groups. The representative swimming paths in the training trials at day 5 were as shown in Fig. $6 \mathrm{~A}$. Mice in APP/PS1 group

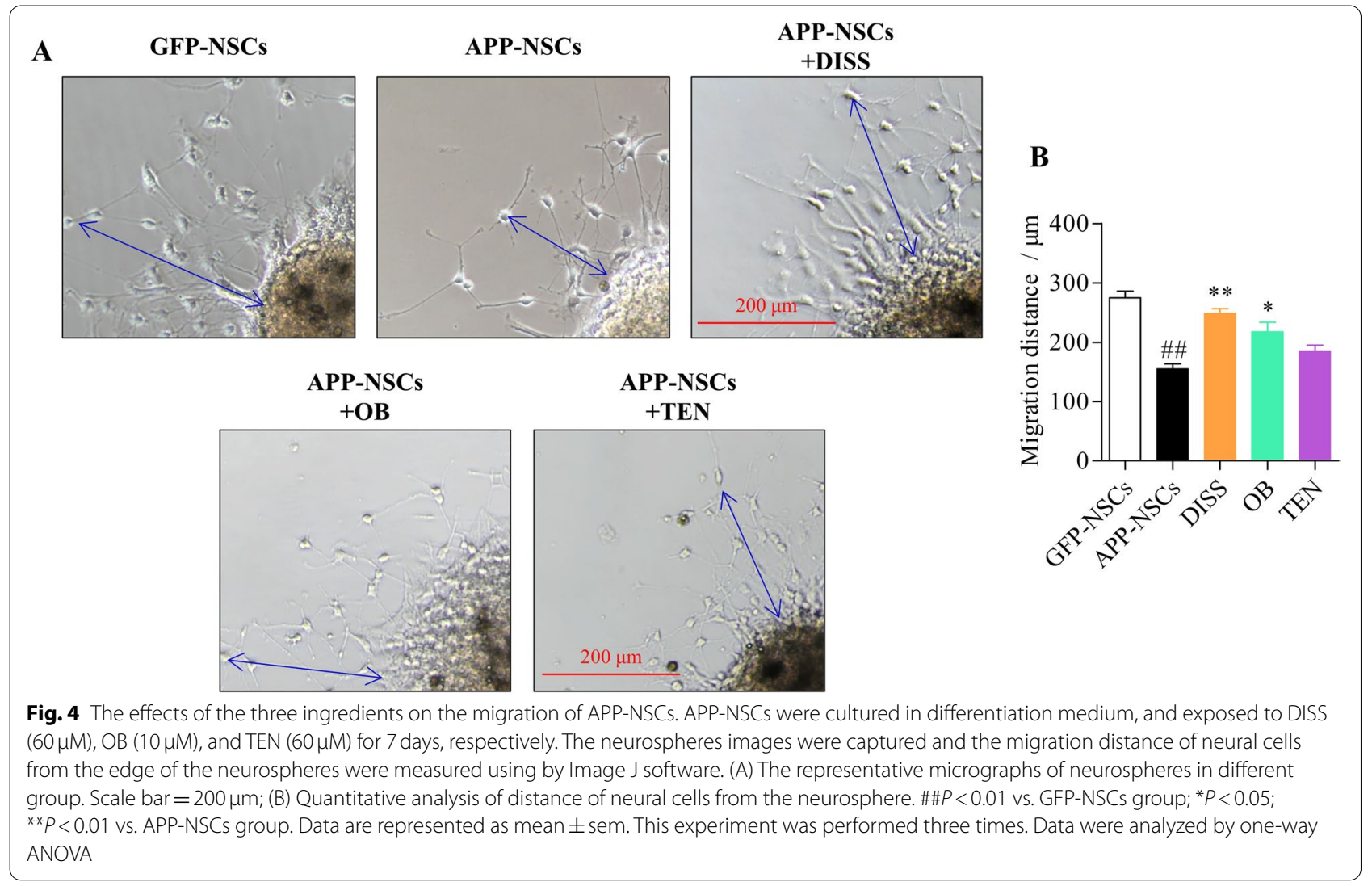




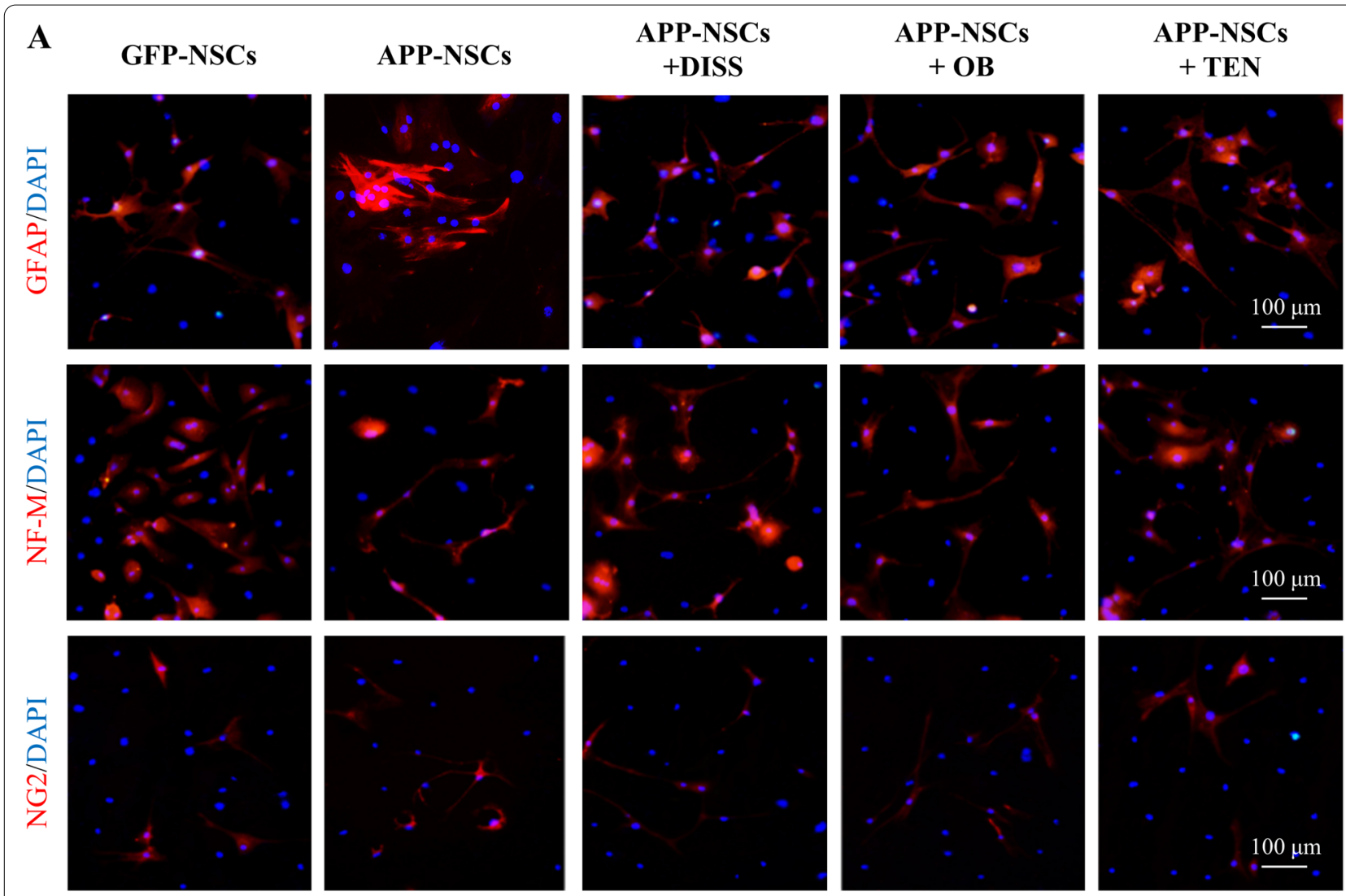

B

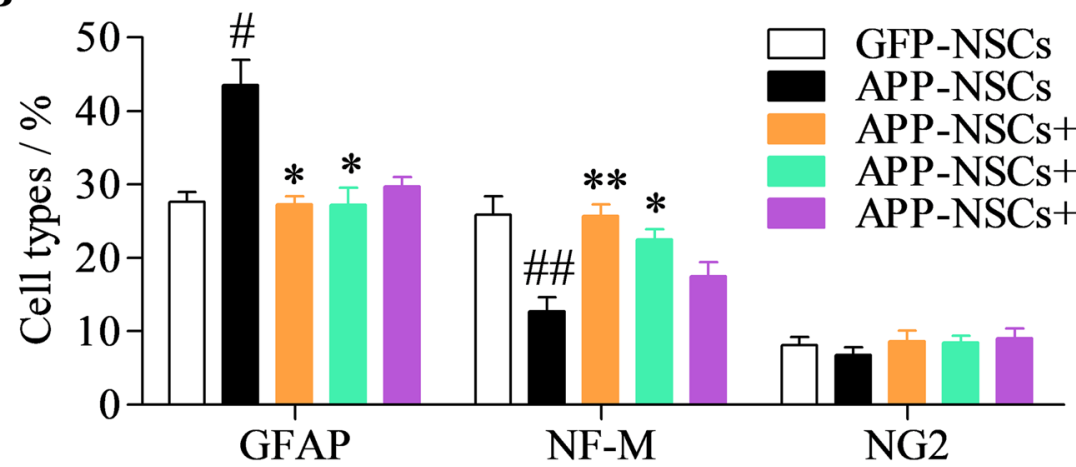

Fig. 5 The effects of the three active ingredients on the differentiation of APP-NSCS. APP-NSCs were cultured in differentiation medium, exposed to DISS $(60 \mu \mathrm{M}) ; \mathrm{OB}(10 \mu \mathrm{M})$, and TEN $(60 \mu \mathrm{M})$ for 7 days, then the cell types were detected using by IF analysis against GFAP, NF-M and NG2 antibody, respectively. (A) The representative micrographs of APP-NSCs differentiated into astrocytes (GFAP ${ }^{+}$); neuronal cells (NF-M ${ }^{+}$) and oligodendrocytes $\left(\mathrm{NG}^{+}\right)$. Scale bar $=100 \mu \mathrm{m}$; (B) The quantitative analysis of astrocytes, neurons, and oligodendrocytes as in A. \#P<0.05, \#\#P<0.01 vs. GFP-NSCs group; ${ }^{*} P<0.05 ;{ }^{* *} P<0.01$ vs. APP-NSCs group. Data are represented as mean \pm sem. This experiment was performed three times. Data were analyzed by one-way ANOVA

exhibited no preference towards the target quadrant with longer escape latency (Fig. $6 \mathrm{~B}, \# \# P<0.01$ vs. WT group from day 3 to day 5), longer swimming distances (Fig. 6 $\mathrm{C}$, \#\# $<0.01$ vs. WT group), shorter time spent in the target quadrant (Fig. $6 \mathrm{D}, \# \# P<0.01$ vs. WT group), and fewer platform crossing numbers (Fig. $6 \mathrm{E}$, \#\#P<0.01 vs. WT group) compared with WT group, indicating severe cognitive damages in APP/PS1 mice. Fortunately, DISS treatment dose-dependently ameliorated the cognitive deficits of APP/PS1 mice (Fig. 6 A-E, ${ }^{*} P<0.05$, ${ }^{* *} P<0.01$ 

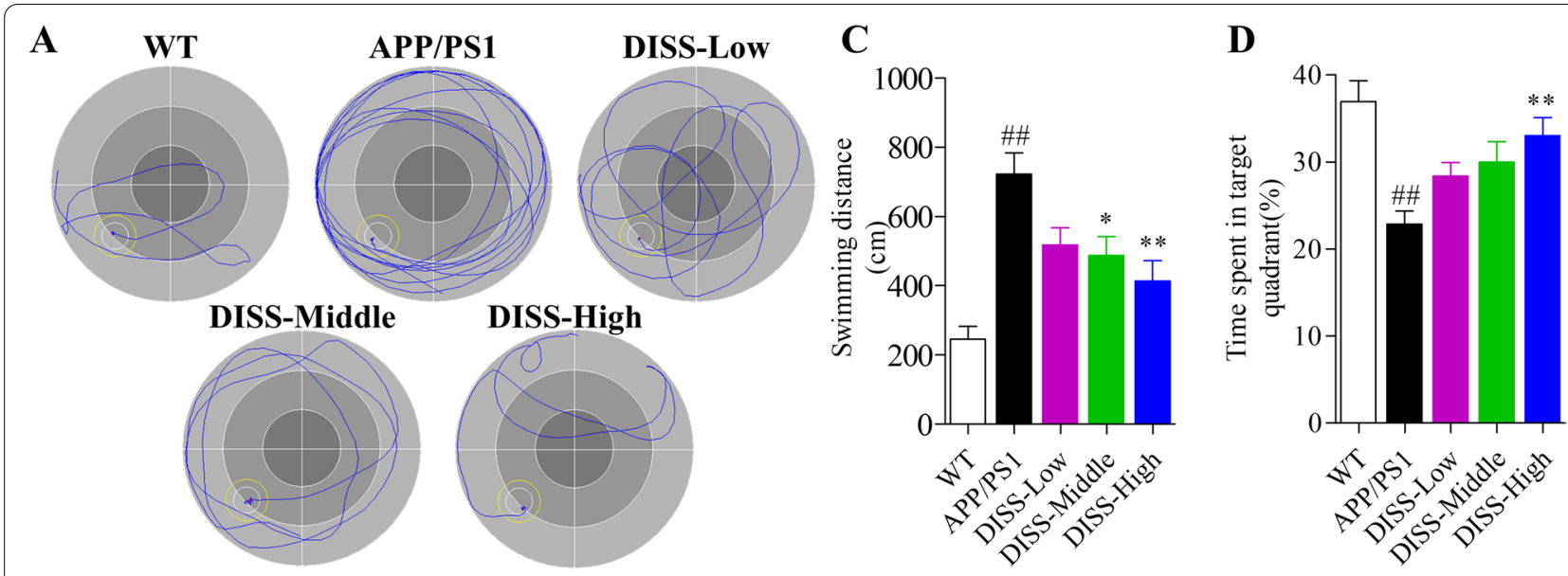

B

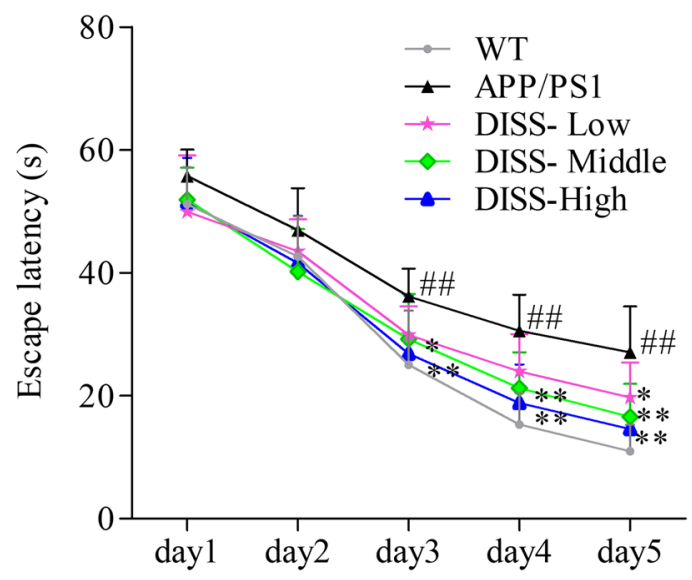

$\mathbf{E}$

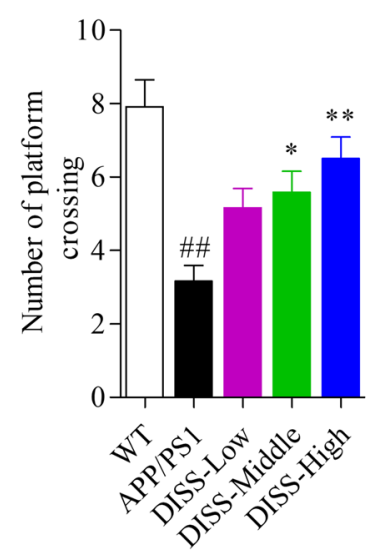

$\mathbf{F}$

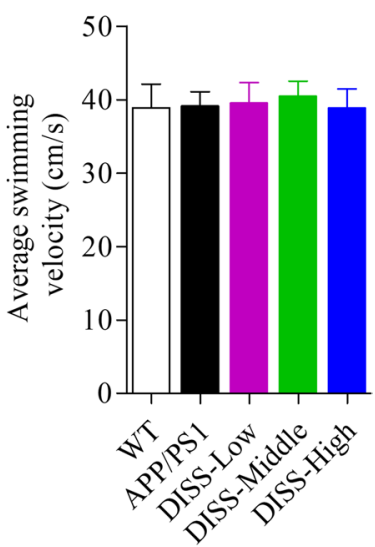

Fig. 6 DISS rescued cognitive deficits in APP/PS1 mice. After 4-weeks treatment, MWM test was carried out to examine the cognitive function of mice in each group. (A) The representative swimming paths of each group in the training trails at day 5; (B) The escape latency in the training trials; (C) The swimming distances before crossing the platform; (D) The time spent in the target quadrant; (E) The times of platform crossing; (F) The swimming velocity in the probe trails. $\# P<0.05 ; \# \# P<0.01 \mathrm{vs.} \mathrm{WT} \mathrm{group;}{ }^{*} P<0.05 ;{ }^{*} P<0.01 \mathrm{vs}$. APP/PS1 group. Data are represented as mean \pm sem. $n=10$ mice in each group. The escape latencies in different groups were analyzed by repeated-measures two-way ANOVA, and the other data were analyzed by one-way ANOVA

vs. APP/PS1 group). There was no remarkable difference among the swimming velocity in each group (Fig. 6 F), which indicated that DISS had no significant effects on motor ability of mice.

\section{DISS ameliorated pathological deficits of hippocampal neurons in adult APP/PS1 mice}

Nissl body, a representative structure of neurons, consists of a host of rough endoplasmic reticulum and free ribosomes, and plays a vital role in protein synthesis. Thus, it can be served as an indicator reflecting the size, number, morphology, location and survival of neurons $[39,40]$. A large number of Nissl-positive cells can be observed in the hippocampal CA1, CA3 and DG areas in TW group (Fig. 7 A-F). However, the number of Nissl bodies were severely decreased in the hippocampal CA1, CA3 and DG areas in the brain of APP/PS1 mice (Fig. 7 A-F, CA1: $\# \#<<0.01$; CA3: $\# P<0.05$; DG: $\# P<0.05$ vs. WT group). Whereas, administration with DISS $(20 \mathrm{mg} / \mathrm{kg})$ strikingly elevated the number of Nissl bodies compared to APP/PS1 group (Fig. 7 A-F, " $P<0.05$ vs. APP/PS1 group). These results demonstrated that DISS effectively reduced the pathological damages of hippocampal neurons in APP/PS1 mice.

\section{DISS enhanced hippocampal NSCs proliferation in adult APP/PS1 mice}

IF staining assays against Sox-2 and Nestin were carried out to detect the NSCs in the hippocampus. The immunostaining results showed that NSCs labeled by Sox-2 


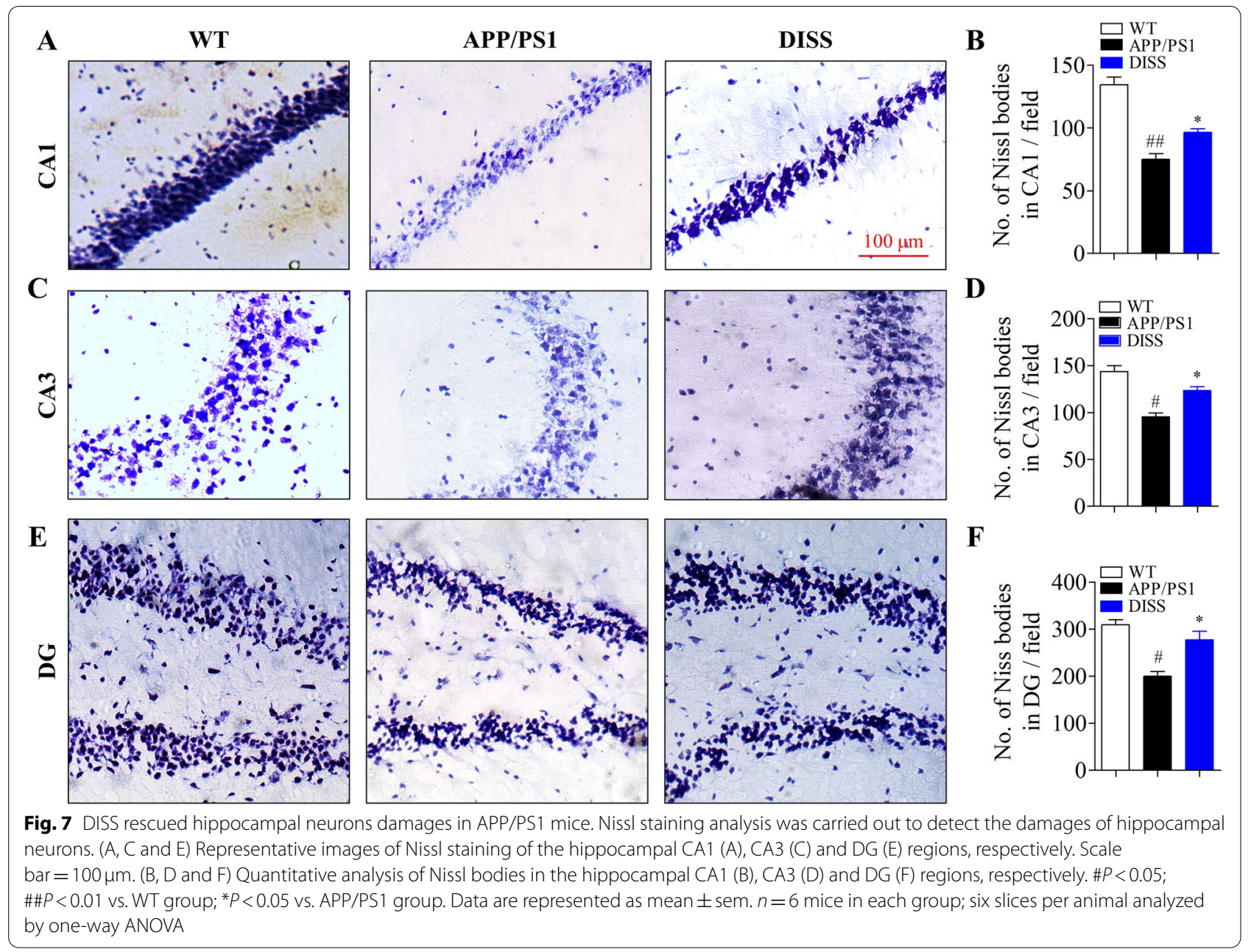

in the DG areas in APP/PS1 group were obviously lessened compared to WT group (Fig. 8 A-B, \#\#P<0.01 vs. WT group). However, DISS $(20 \mathrm{mg} / \mathrm{kg})$ treatment for 4 weeks considerably augmented the number of Sox2 -positive cells (Fig. 8 A-B, $" P<0.01$ vs. APP/PS1 group). Similarly, fewer Nestin-positive cells were observed in hippocampal DG regions in APP/PS1 group (Fig. 8 C-D, $\# \# P<0.01$ vs. WT group), but more Nestin-positive cells were detected in the DISS treatment group (Fig. 8 C-D, ${ }^{*} P<0.05$ vs. APP/PS1 group). These results demonstrated that DISS could promote the NSCs proliferation in the hippocampal DG regions in APP/PS1 mice.

\section{DISS increased the number of neurons in adult APP/PS1 mice}

Mature neurons were detected using by IF staining against NeuN. The results showed that NeuN-positive cells in the hippocampal CA1, CA3 and DG regions were strikingly reduced in APP/PS1 group (Fig. 9 A-F, CA1: $\# \# P<0.01$; CA3: $\# P<0.05$; DG: $\# P<0.05$ vs. WT group), indicating neurogenesis deficits in APP/PS1 mice. Fortunately, DISS $(20 \mathrm{mg} / \mathrm{kg})$ treatment for 4 weeks effectively augmented the number of mature neurons $\left(\mathrm{NeuN}^{+} /\right.$ DAPI) (Fig. 9 A-F, ${ }^{*} P<0.05$ vs. APP/PS1 group), indicating a positive stimulation of DISS on hippocampal neurogenesis in APP/PS1 mice.

\section{Discussion}

In adult brain, hippocampal neurogenesis takes place throughout the whole life and plays critical roles in sustaining and restoring the cognitive function [10, 41]. However, compromised neurogenesis was observed in both $\mathrm{AD}$ patients and $\mathrm{AD}$ animals. Emerging evidence demonstrates that hippocampal neurogenesis is impaired prior to the onset of $\mathrm{AD}$ pathology, and contributes to the initiation and development of neuropathology in $\mathrm{AD}$ [42-45]. In the present study, we evaluated the effects of three active chemical constituents (DISS, OB and TEN) of PT on the survival, proliferation, migration and neuronal differentiation of APP-NSCs in vitro, and further 


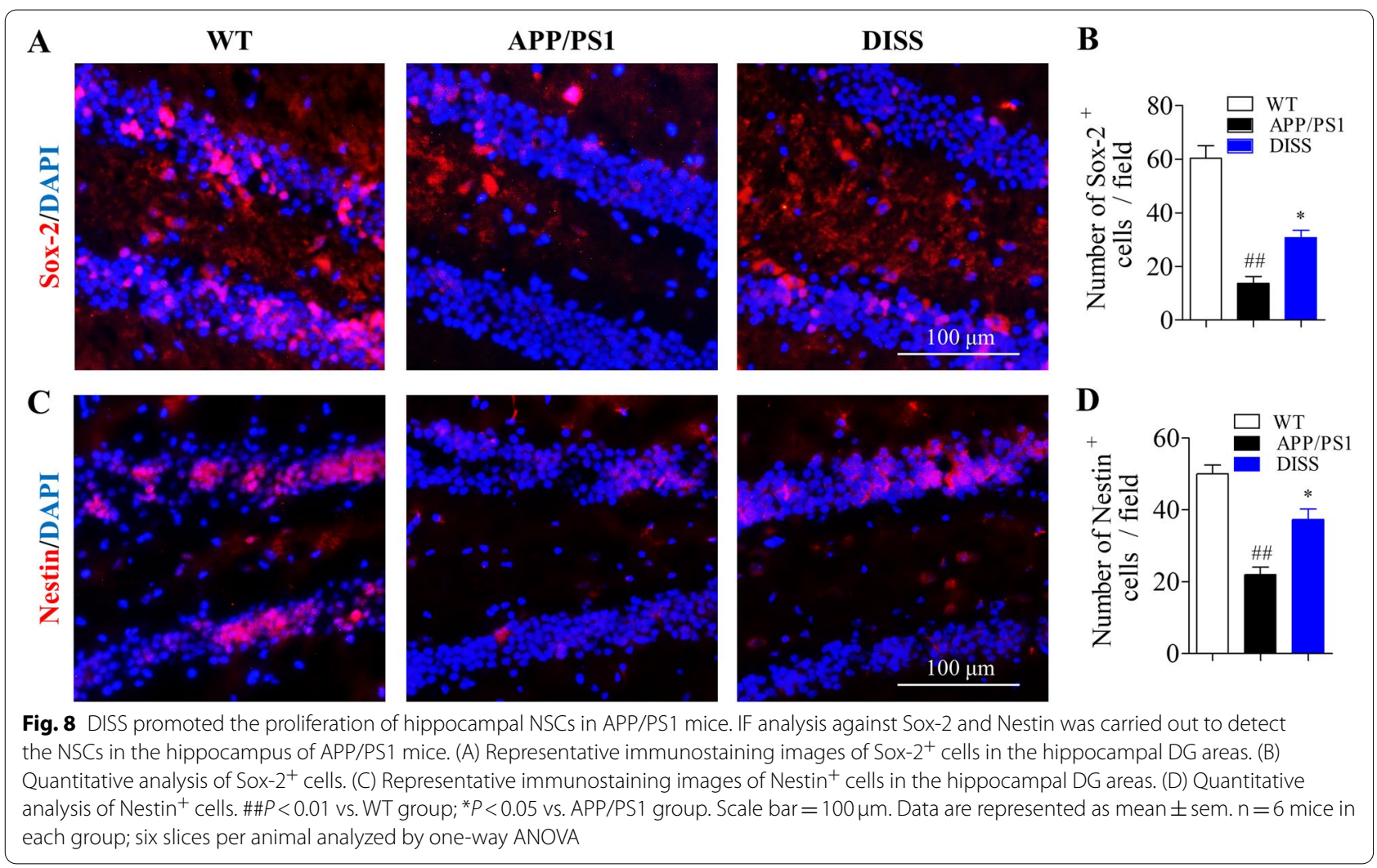

identified the potential active chemical of PT to promote neurogenesis in vivo. We demonstrated that DISS cloud stimulate the proliferation, migration and neuronal differentiation of APP-NSCs, and rejuvenate hippocampal neurogenesis to promote the cognitive function in adult APP/PS1 mice.

The amyloid hypothesis posits that the excessive accumulation of $A \beta$ leads the progressive dysfunction and degeneration of neurons in $\mathrm{AD}[32,38,46,47]$. Furthermore, it has been revealed that $A \beta_{42}$ oligomers compromise the mtDNA repair, shift NSCs differentiation towards an astrocytic lineage [48], as well as impair the migratory capacity of NSCs [49]. Considering the vital role of $A \beta$ in the progress of $A D$, we established an $A D$ cell model using by lentiviral transfection of mutant APP gene into NSCs named as APP-NSCs. Consistent with our previous studies $[29,30]$, the APP-NSCs continuously express APP mutant gene disturbing the APP metabolism such that lead to high levels of $A \beta$ in the cells (Fig. 1 D-E), which ultimately impaired the cell viability, proliferation, and differentiation of APP-NSCs.

The DISS, OB and TEN are the main constituents of PT, which is a famous traditional Chinese medicine with multiple neuroprotective effects on central nervous system diseases. DISS has been revealed to improve the cell viability and protect SH-SY5Y cells from apoptosis induced by glutamate and $\mathrm{H}_{2} \mathrm{O}_{2}$ [24, 25], as well as ameliorate hippocampal plasticity in rats suffering from chronic mild stress [50]. OB has been reported to mitigate the cognitive impairments in APP/PS1 mice [22], aging rats induced by D-galactose [23], as well as LPS-injured rats [51]. The suppressing effects of OB on neuroinflammation, apoptosis, oxidative stress and $A \beta$ pathology may relate to NF-kB/p65, Nrf-2/HO-1, Bcl-2/ $\mathrm{Bax} /$ caspase-9 signaling pathways $[22,23,51]$. TEN is a metabolite of OB [26], and oral administration of TEN markedly increased the learning and memory ability in $\mathrm{AD}$ animals by anti-apoptosis [27], anti-neuroinflammation [28] and reduction of $A \beta$ secretion [16, 52-54]. The activities of anti-apoptosis, anti-neuroinflammation, anti-oxidative stress, anti-A $\beta$ pathology are beneficial for hippocampal neurogenesis, however, there is little literature about whether these compounds could rescue the damages of hippocampal neurogenesis in APP/PS 1 mice.

In present study, we demonstrated that DISS, OB and TEN could all enhance the cell viability (Fig. 2 ), rescue the dysfunction of proliferation (Fig. 3) of APP-NSCs. Interestingly, only DISS and OB were observed to facilitate the migration (Fig. 4) and neuronal differentiation of APPNSCs (Fig. 5). Hippocampal neurogenesis is a multistep process involving NSC proliferation, migration, neuronal differentiation, neuronal mature and integration into the 


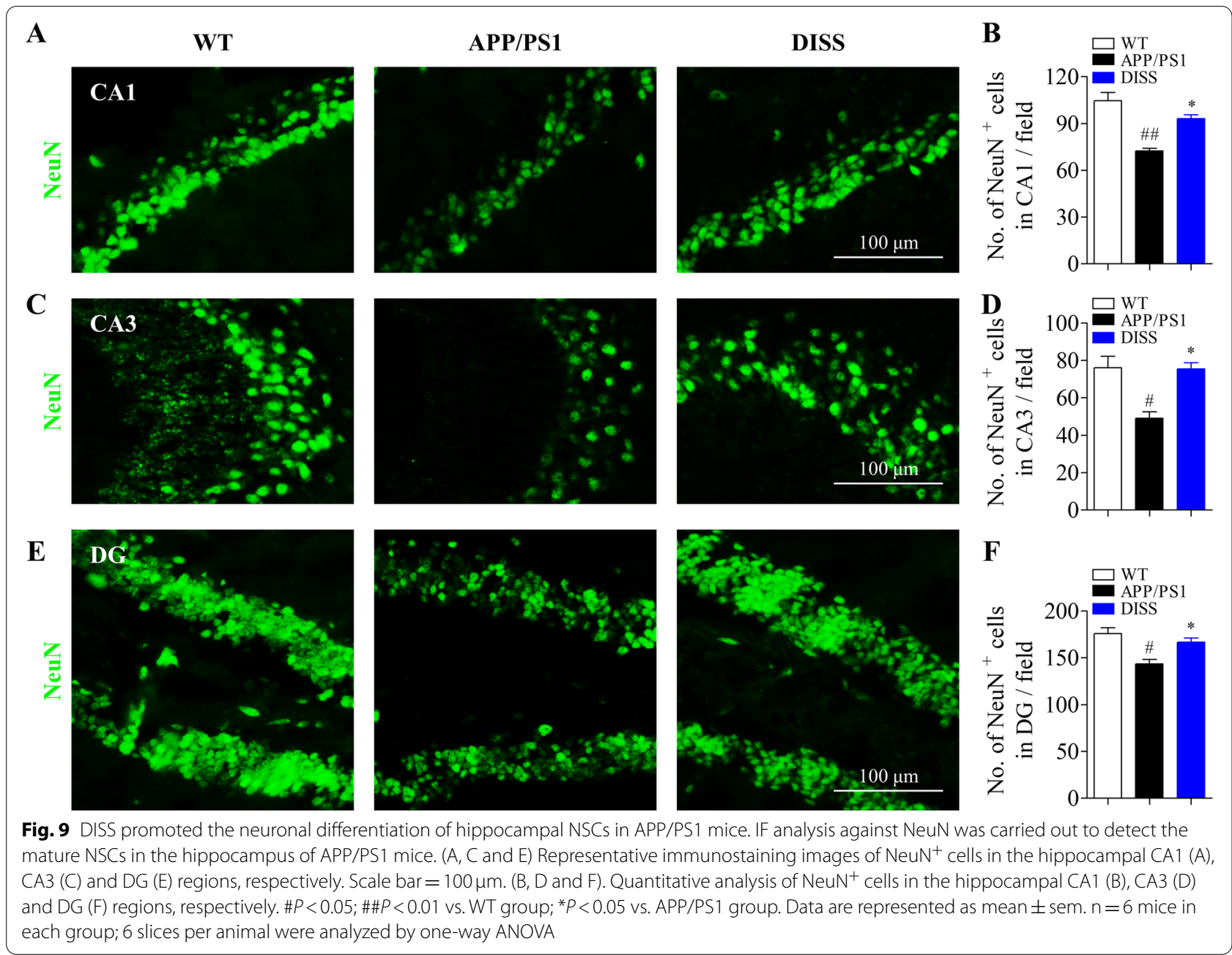

preexisting neural circuits $[8,55,56]$. The proliferation, migration and neuronal differentiation capable of NSCs in vitro can reflect the neurogenesis ability in vivo, and compounds which can positively modulate these processes in vitro likely to strength the neurogenesis in vivo $[14,32]$. Among the three compounds investigated in present study, DISS displayed the optimal potence to enhance the neurogenesis in vitro, thus, we chose DISS to investigate whether it could stimulate hippocampal neurogenesis in the brain of adult APP/PS1 mice.

The APP/PS1 mouse is a common rodent model to study the neuropathology and therapeutic strategies of AD. The APP/PS1 mouse expresses both human APPswe and PS1 $\triangle \mathrm{E} 9$ mutated genes, which alter APP metabolism and result in overproduction of $A \beta$ with age, and $A \beta$ plaques can be observed at about 9 months of age [57-59]. Our findings indicated that gavage administration of DISS $(20 \mathrm{mg} / \mathrm{kg})$ for 4 weeks strikingly mitigated the learning and memory dysfunctions of APP/PS1 mice (Fig. 6), increased the amount of Nissl bodies (Fig. 7). In addition, DISS $(20 \mathrm{mg} / \mathrm{kg})$ treatment for 4 weeks remarkably fostered hippocampal NSCs proliferation and neuronal differentiation presented by increased number of Sox- $2^{+}, \mathrm{Nestin}^{+}$and $\mathrm{NeuN}^{+}$ cells in the hippocampus (Fig. 8 and Fig. 9). Sox-2 and Nestin are the biomarkers of NSCs, and NeuN is the biomarker of mature neurons. These data indicated that DISS could promote hippocampal neurogenesis in APP/PS1 mice. It has been revealed that DISS can increase the expression of BDNF and promoted phosphorylation of CREB via the CaMKII and ERK1/2 pathway [25], which beneficial for hippocampal neurogenesis $[60,61]$.

In summary, our findings indicated that DISS is the potential active ingredient of PT to promote neurogenesis, and DISS has the property to rejuvenate hippocampal neurogenesis to mitigate the learning and memory damages in adult APP/PS1 mice. However, the molecular mechanisms underlying the neurogenesis 
medicated by DISS in AD pathology still need to be clarified in the future.

\section{Conclusions}

Our findings demonstrated DISS is the constituent of PT that triggers the most potent increase of hippocampal neurogenesis in APP/PS1 transgenic mice.

\begin{abstract}
Abbreviations
AD: Alzheimer's disease; DISS: 3;6'-Disinapoyl sucrose; OB: Onjisaponin B; TEN Tenuifolin; PT: Polygala tenuifolia; NSCs: Neural stem cells; APP-NSCs: NSCs transfected with amyloid precursor protein (APP) gene; MTT: 3-(4,5- Dimethylthiazol-2-yl)-2,5-diphenyltetrazolium bromide; LDH: Lactate dehydrogenase; IF: Immunofluorescence; BrdU: 5-Bromo-2'-deoxyuridine; MWM: Morris water maze; NFTs: Neurofibrillary tangles; SPs: Senile plaques; AB: Amyloid beta; FBS: Fetal bovine serum; EGF: Epidermal growth factor; bFGF: Basic fibroblast growth factor; GFAP: Glial fibrillary acidic protein; NF-M: Intermediate neurofilament; Sox-2: Sex-determining region Y-box 2; NG-2: Neural/glial antigen-2; NeuN: Neuron-specific nuclear protein; WT: Wild-type; NEAA: Non-essential amino acid; GFP: Green fluorescent protein; PFA: Paraformaldehyde.
\end{abstract}

\section{Supplementary Information}

The online version contains supplementary material available at https://doi. org/10.1186/s12906-021-03437-5.

\section{Additional file 1.}

\section{Acknowledgments}

We would like to thank Dr. Ya-Ping Yan for the gift of the GFP and GFP-APP plasmids.

\section{Authors' contributions \\ H.H. Xiao; X. F. Wang; X. L. Hu; and J.X. Yang participated in the research design. Y.T. Wu; H.H. Xiao; X. F. Wang; J.C. Chen; and L. Kong performed the experiments. Y.T. Wu; H.H. Xiao; X. F. Wang and L. Kong analyzed the data. H.H. Xiao and Y.T. Wu contributed to the writing of the manuscript. All the authors reviewed the manuscript. The author(s) read and approved the final manuscript.}

\section{Funding}

This work was supported by the Natural Science Foundation of Education Department of Liaoning Province (No. L201945 and L202036) and the Dalian Science and Technology Innovation Foundation (No. 2018J13N126).

\section{Availability of data and materials}

The datasets used and/or analyzed during the current study available from the corresponding author upon reasonable request.

\section{Declarations}

Ethics approval and consent to participate

All animal experiments have been approved by the Animal Core and Welfare Committee of Liaoning University of Traditional Chinese Medicine (use license number: SYXK (Liao) 2019-0004). All animal experiments complied with the ARRIVE guidelines, and were carried out in accordance with Guide for the Care and Use of Laboratory Animals published by the US National Institutes of Health (NIH Publication No. 85-23, revised 1996).

\section{Consent for publication}

Not applicable.

\section{Competing interests}

The authors declare they have no competing financial interests.
Received: 5 July 2021 Accepted: 6 October 2021

Published online: 25 October 2021

\section{References}

1. Sung PS, Lin PY, Liu CH, Su HC, Tsai KJ. Neuroinflammation and neurogenesis in Alzheimer's disease and potential therapeutic approaches. Int J Mol Sci. 2020;21(3):1-23.

2. Kent SA, Spires-Jones TL, Durrant CS. The physiological roles of tau and $A \beta$ : implications for Alzheimer's disease pathology and therapeutics. Acta Neuropathol. 2020;140(4):417-47.

3. Kandimalla R, Manczak M, Fry D, Suneetha Y, Sesaki H, Reddy PH. Reduced dynamin-related protein 1 protects against phosphorylated tau-induced mitochondrial dysfunction and synaptic damage in Alzheimer's disease. Hum Mol Genet. 2016;25(22):4881-97.

4. Manczak M, Kandimalla R, Yin X, Reddy PH. Hippocampal mutant APP and amyloid beta-induced cognitive decline, dendritic spine loss, defective autophagy, mitophagy and mitochondrial abnormalities in a mouse model of Alzheimer's disease. Hum Mol Genet. 2018;27(8):1332-42.

5. Young JK. Neurogenesis makes a crucial contribution to the neuropathology of Alzheimer's disease. J Alzheimers Dis Rep. 2020;4(1):365-71.

6. Choi SH, Tanzi RE. Is Alzheimer's disease a neurogenesis disorder? Cell Stem Cell. 2019:25(1):7-8.

7. Scopa C, Marrocco F, Latina V, Ruggeri F, Corvaglia V, La Regina F, et al. Impaired adult neurogenesis is an early event in Alzheimer's disease neurodegeneration, mediated by intracellular $A \beta$ oligomers. Cell Death Differ. 2020;27(3):934-48.

8. Ming GL, Song H. Adult neurogenesis in the mammalian brain: significant answers and significant questions. Neuron. 2011;70(4):687-702.

9. Tobin MK, Musaraca K, Disouky A, Shetti A, Bheri A, Honer WG, et al. Human hippocampal neurogenesis persists in aged adults and Alzheimer's disease patients. Cell Stem Cell. 2019;24(6):974-82. e3.

10. Moreno-Jiménez EP, Flor-García M, Terreros-Roncal J, Rábano A, Cafini F, Pallas-Bazarra N, et al. Adult hippocampal neurogenesis is abundant in neurologically healthy subjects and drops sharply in patients with Alzheimer's disease. Nat Med. 2019;25(4):554-60.

11. Sorrells SF, Paredes MF, Cebrian-Silla A, Sandoval K, Qi D, Kelley KW, et al. Human hippocampal neurogenesis drops sharply in children to undetectable levels in adults. Nature. 2018;555(7696):377-81.

12. Marlatt MW, Lucassen PJ. Neurogenesis and Alzheimer's disease: biology and pathophysiology in mice and men. Curr Alzheimer Res. 2010;7(2):113-25.

13. Fatt M, Hsu K, He L, Wondisford F, Miller FD, Kaplan DR, et al. Metformin acts on two different molecular pathways to enhance adult neural precursor proliferation/self-renewal and differentiation. Stem Cell Rep. 2015;5(6):988.

14. Mao J, Huang S, Liu S, Feng XL, Yu M, Liu J, et al. A herbal medicine for Alzheimer's disease and its active constituents promote neural progenitor proliferation. Aging Cell. 2015;14(5):784-96.

15. Li C, Yang J, Yu S, Chen N, Xue W, Hu J, et al. Triterpenoid saponins with neuroprotective effects from the roots of Polygala tenuifolia. Planta Med. 2008:74(2):133-41.

16. Wang L, Jin GF, Yu HH, Lu XH, Zou ZH, Liang JQ, et al. Protective effects of tenuifolin isolated from Polygala tenuifolia Willd roots on neuronal apoptosis and learning and memory deficits in mice with Alzheimer's disease. Food Funct. 2019:10(11):7453-60.

17. Cheong MH, Lee SR, Yoo HS, Jeong JW, Kim GY, Kim WJ, et al. Antiinflammatory effects of Polygala tenuifolia root through inhibition of NF-KB activation in lipopolysaccharide-induced BV2 microglial cells. J Ethnopharmacol. 2011;137(3):1402-8.

18. Zhang D, Wang X, Li R, Wang L, Zhou Z, Fu Q, et al. Extract of the aerial part of Polygala tenuifolia attenuates $\mathrm{d}$-galactose/ $\mathrm{NaNO}$-induced learning and memory impairment in mice. Planta Med. 2020;86(18):1389-99.

19. Zeng H, Li P, Zhou L, Ding K. A novel pectin from Polygala tenuifolia blocks $A \beta(42)$ aggregation and production by enhancing insulin-degradation enzyme and neprilysin. Int J Biol Macromol. 2020;161:35-43.

20. Park HJ, Lee K, Heo H, Lee M, Kim JW, Whang WW, et al. Effects of Polygala tenuifolia root extract on proliferation of neural stem cells in the hippocampal CA1 region. Phytother Res. 2008;22(10):1324-9. 
21. Zhao X, Cui Y, Wu P, Zhao P, Zhou Q, Zhang Z, et al. Polygalae Radix: a review of its traditional uses, phytochemistry, pharmacology, toxicology, and pharmacokinetics. Fitoterapia. 2020;147:104759.

22. Li X, Cui J, Yu Y, Li W, Hou Y, Wang X, et al. traditional Chinese nootropic medicine Radix Polygalae and its active constituent onjisaponin $B$ reduce $\beta$-amyloid production and improve cognitive impairments. PLoS One. 2016;11(3):e0151147.

23. Li G, Yu J, Zhang L, Wang Y, Wang C, Chen Q. Onjisaponin B prevents cognitive impairment in a rat model of D-galactose-induced aging. Biomed Pharmacother. 2018;99:113-20.

24. Hu Y, Li J, Liu P, Chen X, Guo DH, Li QS, et al. Protection of SH-SY5Y neuronal cells from glutamate-induced apoptosis by 3,6'-disinapoyl sucrose, a bioactive compound isolated from Radix Polygala. J Biomed Biotechnol. 2012:2012:1-5.

25. Hu Y, Liu MY, Liu P, Dong X, Boran AD. Neuroprotective effects of 3,6'-disinapoyl sucrose through increased BDNF levels and CREB phosphorylation via the CaMKII and ERK1/2 pathway. J Mol Neurosci. 2014;53(4):600-7.

26. Peng F, Lu L, Wei F, Wu D, Wang K, Tang J. The onjisaponin B metabolite tenuifolin ameliorates dopaminergic neurodegeneration in a mouse model of Parkinson's disease. Neuroreport. 2020;31(6):456-65.

27. Liu YM, Li ZY, Hu H, Xu SP, Chang Q, Liao YH, et al. Tenuifolin, a secondary saponin from hydrolysates of polygalasaponins, counteracts the neurotoxicity induced by $A \beta 25-35$ peptides in vitro and in vivo. Pharmacol Biochem Be. 2015;128:14-22.

28. Chen S, Jia J. Tenuifolin attenuates amyloid- $\beta 42$-induced neuroinflammation in microglia through the NF-kB signaling pathway. J Alzheimers Dis. 2020;76(1):195-205.

29. Xiao HH, Zhang MB, Xu JT, Deng Y, Li N, Gao P, et al. Icarisid II promotes proliferation and neuronal differentiation of neural stem cells via activating Wnt/ $\beta$-catenin signaling pathway. Phyto Res. 2021. https://doi.org/10. 1002/ptr.7022.

30. Xiao H, Li H, Song H, Kong L, Yan X, Li Y, et al. Shenzao jiannao oral liquid, an herbal formula, ameliorates cognitive impairments by rescuing neuronal death and triggering endogenous neurogenesis in AD-like mice induced by a combination of A 42 and scopolamine. J Ethnopharmacol. 2020;259:112957

31. Jingxian $Y$, Zhilong J, Fitzgerald DC, Cungen $M$, Shuo $Y$, Hongmei $L$, et al. Adult neural stem cells expressing $\mathrm{IL}-10$ confer potent immunomodulation and remyelination in experimental autoimmune encephalitis. J Clin Invest. 2009;119(12):3678.

32. Shashi Kant T, Brashket $S$, Swati A, Anuradha Y, Madhumita K, Shailendra Kumar G, et al. Ethosuximide induces hippocampal neurogenesis and reverses cognitive deficits in an amyloid- $\beta$ toxin-induced Alzheimer rat model via the phosphatidylinositol 3-kinase (PI3K)/Akt/Wnt/ $\beta$-catenin pathway. J Biol Chem. 2015:290(47):28540-58.

33. Zhang SQ, Lin KL, Law CY, Liu B, Fu XQ, Tse WS, et al. Oleanolic acid enhances neural stem cell migration, proliferation, and differentiation in vitro by inhibiting GSK3 $\beta$ activity. Cell Death Discov. 2018;4:48.

34. Liu P, Hu Y, Guo DH, Lu BR, Rahman K, Mu LH, et al. Antioxidant activity of oligosaccharide ester extracted from Polygala tenuifolia roots in senescence-accelerated mice. Pharm Biol. 2010;48(7):828-33.

35. Barnhart CD, Yang D, Lein PJ. Using the Morris water maze to assess spatial learning and memory in weanling mice. PLoS One. 2015;10(4):e0124521.

36. Vorhees CV, Williams MT. Morris water maze: procedures for assessing spatial and related forms of learning and memory. Nat Protoc. 2006;1(2):848-58.

37. Tong J, Liu W, Wang X, Han X, Hyrien O, Samadani U, et al. Inhibition of Nogo-66 receptor 1 enhances recovery of cognitive function after traumatic brain injury in mice. J Neurotraum. 2013;30(4):247-58.

38. Park SJ, Jung JM, Lee HE, Lee YW, Dong HK, Kim JM, et al. The memory ameliorating effects of INM-176, an ethanolic extract of Angelica gigas, against scopolamine- or A 1-42 -induced cognitive dysfunction in mice. J Ethnopharmacol. 2012;143(2):611-20.

39. Liu P, Cui L, Liu B, Liu W, Hayashi T, Mizuno K, et al. Silibinin ameliorates STZ-induced impairment of memory and learning by up- regulating insulin signaling pathway and attenuating apoptosis. Physiol Behav. 2020:213:112689.
40. Li J, Wen PY, Li WW, Zhou J. Upregulation effects of Tanshinone IIA on the expressions of NeuN, Nissl body, and IKB and downregulation effects on the expressions of GFAP and NF-KB in the brain tissues of rat models of Alzheimer's disease. Neuroreport. 2015;26(13):758-66.

41. Zhao C, Deng W, Gage FH. Mechanisms and functional implications of adult neurogenesis. Cell. 2008;132(4):645-60.

42. Quintero GC. Role of nucleus accumbens glutamatergic plasticity in drug addiction. Neuropsychiatr Dis Treat. 2013;9:1499-512.

43. Unger MS, Marschallinger J, Kaindl J, Höfling C, Rossner S, Heneka MT, et al. Early changes in hippocampal neurogenesis in transgenic mouse models for Alzheimer's disease. Mol Neurobiol. 2016;53(8):5796-806.

44. Lazarov O, Marr RA. Neurogenesis and Alzheimer's disease: at the crossroads. Exp Neurol. 2010;223(2):267-81.

45. Disouky A, Lazarov O. Adult hippocampal neurogenesis in Alzheimer's disease. Prog Mol Biol Transl Sci. 2021;177:137-56.

46. Andreeva TV, Lukiw WJ, Rogaev El. Biological basis for amyloidogenesis in Alzheimer's disease. Biochemistry (Mosc). 82(2):122-39.

47. Choi SH, Kim YH, Hebisch M, Sliwinski C, Lee S, D'Avanzo C, et al. A threedimensional human neural cell culture model of Alzheimer's disease. Nature. 2014;515(7526):274-8

48. Lu J, Li Y, Mollinari C, Garaci E, Merlo D, Pei G. Amyloid- $\beta$ oligomersinduced mitochondrial DNA repair impairment contributes to altered human neural stem cell differentiation. Curr Alzheimer Res. 2019;16(10):934-49.

49. Wang Z, Chen Y, Li X, Sultana P, Yin M, Wang Z. Amyloid- $\beta(1-42)$ dynamically regulates the migration of neural stem/progenitor cells via MAPKERK pathway. Chem Biol Interact. 2019;298:96-103.

50. Hu Y, Liao HB, Dai-Hong G, Liu P, Wang YY, Rahman K. Antidepressant-like effects of 3,6'-disinapoyl sucrose on hippocampal neuronal plasticity and neurotrophic signal pathway in chronically mild stressed rats. Neurochem Int. 2010:56(3):461-5.

51. Li X, Sun Y, Wei Y, Zhou L, Liu L, Yin P, et al. Onjisaponin B (OB) is neuroprotective during cognitive loss through immune-mediated and SIRT1 pathways. Curr Neurovasc Res. 2018;15(2):94-102.

52. Lv J, Jia H, Jiang Y, Ruan Y, Liu Z, Yue W, et al. Tenuifolin, an extract derived from tenuigenin, inhibits amyloid-beta secretion in vitro. Acta Physiol (Oxf). 2009;196(4):419-25.

53. Zhang H, Han T, Zhang L, Yu CH, Wan DG, Rahman K, et al. Effects of tenuifolin extracted from radix polygalae on learning and memory: a behavioral and biochemical study on aged and amnesic mice. Phytomedicine. 2008;15(8):587-94.

54. Wang L, Jin G, Yu H, Li Q, Yang H. Protective effect of Tenuifolin against Alzheimer's disease. Neurosci Lett. 2019;705:195-201.

55. Gonçalves JT, Schafer ST, Gage FH. Adult neurogenesis in the hippocampus: from stem cells to behavior. Cell. 2016;167(4):897-914.

56. Mu Y, Gage FH. Adult hippocampal neurogenesis and its role in Alzheimer's disease. Mol Neurodegener. 2011;6:85.

57. Jankowsky JL, Slunt HH, Ratovitski T, Jenkins NA, Copeland NG, Borchelt DR. Co-expression of multiple transgenes in mouse CNS: a comparison of strategies. Biomol Eng. 2001;17(6):157-65.

58. Borchelt DR, Thinakaran G, Eckman CB, Lee MK, Davenport F, Ratovitsky T, et al. Familial Alzheimer's disease-linked presenilin 1 variants elevate Abeta1-42/1-40 ratio in vitro and in vivo. Neuron. 1996;17(5):1005-13.

59. Van Groen T, Kiliaan AJ, Kadish I. Deposition of mouse amyloid beta in human APP/PS1 double and single AD model transgenic mice. Neurobiol Dis. 2006;23(3):653-62.

60. Dworkin S, Mantamadiotis T. Targeting CREB signalling in neurogenesis. Expert Opin Ther Targets. 2010;14(8):869-79.

61. Takahashi K, Kurokawa K, Miyagawa K, Mochida-Saito A, Nemoto Y,

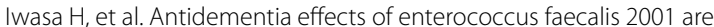
associated with enhancement of hippocampal neurogenesis via the ERK-CREB-BDNF pathway in olfactory bulbectomized mice. Physiol Behav. 2020;223:112997.

\section{Publisher's Note}

Springer Nature remains neutral with regard to jurisdictional claims in published maps and institutional affiliations. 